\title{
Land Use Change in the Mezam Division of the North-West Province, Cameroon From Landsat Imageries (1988 And 2001) 1Olayiwola, A. M.,1Eludoyin, A. 0 and ${ }^{2}$ Ekecha, A. E. \\ doi: 10.4314/ejesm.v4i1.6
}

\begin{abstract}
This study investigated land use change in the Mezam division of the Northwest part of Cameroon. Its main objective was to demonstrate the use of medium resolution but affordable imagery for land use classification. Data were obtained from satellite imageries (Landsat TM 1988 and ETM+2001), and the topographical map of the study area. Both materials were georeferenced to the same coordinate system of the study area and were subjected to Principal Component Analysis for image enhancement. Six landuse classes were identified: Bare Surface, Montane Forest, Water Body, Secondary Forest, Grassland, and Built-Up-Area. A total of 35

training sets were used 32 for 1988 and for 2001. Whereas the built up area and the vegetation areas were derived in vector format, the road network data set was overlaid on the classified images to evaluate the accessibility of the area for forest exploitation and other human activities. The classification accuracies for the two comparable years (1988 and 2001) are 93.75 and 88.57\%, respectively. This fall within the range indicates a strong high accuracy and negligible errors. The study concluded that given the available technology, cost and scale of investigation, a medium resolution image will sufficiently be useful.
\end{abstract}

Keywords: Deforestation, fuel wood, land use, Landsat imagery, Northwest Cameroon.

\section{Introduction}

$\mathrm{O}$ ften defined as the ability to do work, energy occurs in a number of forms, i.e. thermal, radiant, mechanical, electrical, chemical, and nuclear energy. A number of energy sources are renewable (e.g. biomass, water, geothermal, wind, solar) while others are non-renewable (e.g. coal, natural gas, nuclear and oil). Exploitation of these energy sources is however within the context of the technological development of nations or persons using it. For example, about 1.6 billion people in the world, mostly in rural areas, have no access to electricity while about 2.5 billion people still rely on traditional fuelwood, dung and agricultural residues to meet their daily heating and cooking needs. In essence, while energy sources such as nuclear, wind and solar are synonymous with advanced technology, the use of crude oil and coal are associated with developing or crude technology. The high cost of the clean energy has made fuelwood a choice in most developing countries; especially among with the low income earners and relatively poor populations. The use of this source of energy seems traditional in some places while many people are reluctant to change in others. More than $80 \%$ of the population depends solely or to some extent on this form of energy for home use. It is also used in commercial quantities in a number of factories like bakeries, soap factories, barbeques; and such use has subsequently been heightened by the increase in the population and consequent increase in the energy demand (Mhta et al, 2006).

${ }^{1}$ Department of Geography,Obafemi Awolowo University, Ile-Ife, Nigeria amolayiwola@oauife.edu.ng olaadewale@yahoo.com oaeludoyin@yahoo.com

${ }^{2}$ African Regional Centre for Space Technology Education - English, O.A.U. Ile-Ife, Nigeria
Despite the problems associated with the use of the fuel wood, the rate of deforestation in many developing countries for logging and fuel use has demonstrated poor awareness of its consequences. It is in this respect that this study has attempted to investigate the effect of forest use on the land and vegetation resources in one of the threatened environment in Cameroon (i.e. the Mezam Division of the Northwest Province). The Montane forests (on the Cameroon Mountain Range) of the Northwest Province contain the one of the largest percentage of biodiversity in West Africa. The region has witnessed a major trend of forest exploitation, particularly as fuel source. The aim of the study is to demonstrate an application of the relatively new technologies of Remote Sensing and Geographical Information System (GIS) in assessment of the changes that have taken place in the forest extent as well as estimating the fuelwood potential in relation to the physical growth of settlements in the environment. The specific objectives include (a) assessing the land/use land cover for the 2 comparable periods (1988 and 2001) for which data was available; and (b) identifying possible encouragers of deforestation in the study area.

\section{Literature Review}

Deforestation is a complex phenomenon that there is little or no consensus about its components and processes. FAO (2001) for example, describe the phenomenon as the conversion of forest to another land use 
or the long term reduction of tree canopy cover below the minimum $10 \%$ threshold. It is also referred to as complete destruction of forest of canopy cover through clearing for agriculture, grazing, and/or non forest purposes (Mayaux and Malingreau, 1996). In addition, OlaAdams (1981) and Adesina (1991) have identified illegal and uncontrolled exploitation of timber, bush burning as primary causes of deforestation. In many parts of the developing countries, especially in Africa and Asia, one of the most important causes of vegetation degradation is the concern about energy.

The effects of use of vegetation degradation are replete in literature. For example, the UNDP (2005) MDG progress report revealed that about 22 million hectares of forestland in Cameroon are receding by about 100,000 hectares per year as a result of overgrazing, bush fires and exploitation for timber and firewood. In addition, indoor air pollution has implicated to use fuelwood in developing countries. For example, over 1.6 million deaths, resulting from acute respiratory infections, have been attributed to indoor air pollution from solid fuel use in 2000 alone (Smith et al, 2004). A number of these deaths those of children under five years of age.

In Cameroon, like many other developing countries, the use of wood as an energy source by households is common among low income earners and factories. Fuelwood in this part of the world is also known as fire wood. Firewood includes the bye product of logging activities, and leftovers from carpentry works and saw mills (i.e. wood shavings or saw-dust). Other form of fuelwood is charcoal, a semi-transformation of the wood. Charcoal is widely preferred by individual and industrial users it is relatively handy. A national estimate of household solid fuel use of 2003 indicates that $83 \%$ of the households in Cameroon depend on fuelwood (Mehta et al, 2006). The fuelwood and charcoal market is the largest forest products market in terms of physical volume of timber felled, ranging between US\$45 and US\$65 million annually (Millington and Pye, 1994). FAO (1981) noted that in 1980, about 2 billion people in developing countries used fuelwood as their main source of energy. Cameroon, like many developing countries is characterized by high level of poverty, high rural population and low income earners, a situation which has made the use of this 'cheap' source of energy a ubiquitous phenomenon in them (ref). The 'high cost' of the other (cleaner) sources of energy have made them difficult to obtain, rendering more hand to the use of the 'cheap but unclean' energy sources (Smith and Desai, 2001).

\section{Study Area}

The study area is located in the Mezam Division in the North West province of Cameroun (Figure 1). It is located $366 \mathrm{~km}$ north-west of the Yaoundé. The area covers an approximate area of $200 \mathrm{~km}$ square and is situated between $9^{0} 58^{\prime} 16^{\prime \prime} \mathrm{N}, 6^{0} 3^{\prime} 14^{\prime \prime} \mathrm{E}$ and $10^{0} 14^{\prime} 16^{\prime \prime} \mathrm{N}, 5^{0} 51^{\prime} 8^{\prime \prime} \mathrm{E}$. The study area covers about 30 villages. It is bounded in the by Menchum, Boyo and Momo divisions in the North and East, and in the West to the South by the Western Province. The Division has an estimated 446,000 inhabitants and numerous village populations. Most of the villages are rural and the settlement are sparsely populated with expansive agricultural. The urban/semiurban areas make about $25 \%$ of the total area. The urban areas involve less agricultural activities but more of primary industrial activities, including factories, transportation and carpentry.

The study area is characterised by a cool temperate-like climate, influenced mainly by mountainous terrain and rugged topography. Average rainfall is about $2400 \mathrm{~mm}$, temperature average $23^{0} \mathrm{C}$, ranging between $15^{0}-32^{\circ} \mathrm{C}$. There two main seasons; wet season, which starts in March and ends in October, and dry season from November to February. The dry season is characterised by the Hamattan with dry air. Vegetation in this area falls within the grassland region. It comprises shrub, stunted trees, typical of a savanna region. Some of the indigenous trees have been reduced to a vulnerable level to near extinction due through exploitation for timber and fuelwood use.

Located in the Bamenda highlands and montane region which ranges to the west province, the relief of the region is rugged with steep hills and valleys. The region is characterized by the NW-SE fault plane that caused part of the area especially to the South West part to be down thrown forming the famous escarpment to the North East. The altitude of the area varies from 1207 to 2621 meters above the sea level. The drainage of the area is defined by the direction of the slope of the hills. The area is characterized by deep valleys which are oriented towards the SW direction. There are several rivers with the 
Mughep River taking its source from the highest points in the NE of the area make a water fall at the Station point just above Sisia Quarters. This river combines with other smaller rivers to form River Mezam which empties itself into the Menchum falls known to be able to generate huge amounts of hydroelectrical energy. A preliminary investigation of the land use in the study area has revealed that human activities such as farming and construction are continuously exposing watersheds and wetlands. The vegetation, especially the forest is also being exploited for many purposes, especially for use as fuelwood.

\section{Materials and Methods}

The study used Landsat TM 1988 and ETM+ 2001 satellite imageries. Both images had been obtained between December and January, representing the dry season. The imageries were georeferenced to the coordinate system of the study area (WGS84, with projection UTM Zone $32 \mathrm{~N}$ using the Minna as the Datum), with ground control points collected from the field. The ERDAS software was used to carry out this task. The points were collected at significant points like road crossings using GPS with UTM projected coordinate settings. The topographical map of the study area was also georeferenced using the same coordinate system for uniformity/compatibility with the imageries. The images were subjected to image enhancement techniques such as Principal Component Analysis for better visual perception. A supervised classification on the imageries based on maximum likelihood classifier algorithm used six landuse/landcover classes which are; Bare Surface, Montane Forest, Water Body, Secondary Forest, Grassland, and Built Up Area. A total of 35 training sets were used for 2001 and 32 for 1988. The description of the land use is as follows: (a) the bare surface is classified as consisting eroded surfaces, rock outcrops and exposed bare ground, which were detected to have occurred due to overgrazing, farming and bush fires, (b) montane Forest is made up of the evergreen forest with thick undergrowth and as high as $15 \mathrm{~m}$ and above. The ground truthing activities showed that this forest crown percentage is above $50 \%$ containing tree species, including mahogany, pterigota, albizia (small leaf), eucalyptus, voacanga pygeum and pygeum, (c) Secondary Forest is made up of the part of the forest with loose undergrowth that supports agricultural activities. The trees are between $8 \mathrm{~m}$ and $15 \mathrm{~m}$ high. The forest crown is characteristically less than $50 \%$. The major species found in this forest include mainly cash crop trees such as mangoes, guava, pear, kola nut, palm, raffia palms, and orange, (d) Grassland, which contains vegetation that are less than $8 \mathrm{~m}$ in height, including shrubs, grasses, stunted trees and fallow land areas, (e) Built-up Area includes spatial structures such as human structures such as roads, houses, airports, and other construction by human; and (f) Water Body, which includes surfaces covered by water such as rivers, dams, lakes and oceans. The sample points collected in the field and from acquaintance of the terrain were used to validate classification results.

The settlements (built up area) and the vegetation (Montane Forest landuse/landcover types) were derived in vector format for both years (1988 and 2001) and compared in terms of their areal extent. The road network data set was overlaid on the classified images to evaluate the accessibility of the area for forest exploitation and other human activities. The classification accuracies for the two comparable years (1988 and 2001) are 93.75 and 88.57 per cent, respectively. This fall within the range described by Congalton (1996) as strong agreement, indicating a strong high accuracy and negligible errors.

\section{Results And Discussion}

Figures $2 \mathrm{a} \& \mathrm{~b}$ show the result of the overlay of the digitized area of some main settlements and montane forest indicates that change has taken place in the areal extent of the landcover types. The montane forest areal coverage in 1988 has decreased compared to the areal coverage of the forest in 2001. Overlay of the settlements in the study area show a considerable increase in the areal extent of the settlement. This indicates more human/human activities and more human demand. The increase in the areal extent of the settlement closes the gap between the forest area and built up area thus more and easy exploitation. The Figure also indicated the presence of the settlements within the reserves and this brings human activities very close to the forest which are often marked by the exploitation activities thus causing forest degradation. The area was highly accessible despite the mountainous nature of the terrain. This accessibility of the area is one of the causes of the forest reduction which is observed 
almost in all the forest montane patches that were digitized.

In addition, Figure $2 c \& d$ revealed that change in landuse / land cover occurred between 1988 and 2001. Some landuse/landcover types decreased while others have increased, albeit at different percentages/rates. In 1988, classification, Grassland made up the highest landuse/landcover type with 30739.28ha making up $36.88 \%$ of the study area. This was followed by the bare surface and Water body made up the least landuse/landcover type with just 287.54 ha making up just $0.35 \%$ of the study area. Montane Forest made up 5515.99 ha representing $6.62 \%$ of the total study area. In 2001 classification, Secondary Forest made up the largest cover type with 26184.6 ha making up $31.41 \%$ of the total study area while Water which showed a slight increase from 1988, was still the least landuse/landcover type with 394.022 ha making $0.47 \%$ of the study area. Montane forest covered 4283 ha representing $5.14 \%$ of the total area. The built-up area covered about 9066.6 ha representing $10.88 \%$ of the total area. Secondary Forest landuse/landcover type is the highest type with the highest change value according to the classification of the 1988 and 2001 images. It showed an increase in areal cover of 7851.55 ha representing $9.2 \%$ of its areal coverage in 1988. Built up Area had increased by $2 \%$, and while water body, insignificantly. Grassland has however decreased by about $6110 \mathrm{Ha}$ (7.33\%) while the Montane Forest cover has reduced by $1.48 \%$ from its $6.62 \%$ occupation of the total landuse in 1988.

In order to obtain the rate of change of the various landuse/landcover types, the total land area for each landuse category had been divided by 13 , being the number of years that separated the images. From this, the Grassland occupation had showed the highest rate of rate of decrease to $470,4 \mathrm{Ha} / \mathrm{yr}$ (i.e $0.56 \% / \mathrm{yr}$ ). Montane forest had decreased at a rate of 94.8 ha/yr (representing $0.11 \%$ / year; while the secondary forest and built up area extents have increased at $603.97 \mathrm{ha} / \mathrm{yr}$, and $173.69 \mathrm{ha} / \mathrm{yr}$ $(0.72 \% / y r$ and $0.21 \% / y r)$, respectively.

\section{Conclusion}

The following conclusions can be made from the study. The images were collected in the dry season where most of the vegetation was dry and the bushes must have been burnt.
This might have affected the landuse/landcover results thus images of the same study area obtained in December or early January will be complement the results. The study shows that landuse/landcover types will always change but the rate at which the change occurs determines the attention given to it. Some landuse/landcover changes whether at a very low rate will greatly affect the environment and consequently humans. The study has shown a decrease in the montane forest area which is source of energy for the inhabitants of the Mezam division and consequent increase in the Built Up Area thus indicate an increase humans and human activities.

All these consequently require energy to keep on going and the most available energy is Fuelwood. The decrease in the forest indicates that one day if care and appropriate management is not put to monitor the Exploitation of the forest, then this so much needed energy and widely used energy in this area will cease to exist. This study was carried on images captured in the dry season and in a place where the bushes are always burnt in the dry season. Thus there were some discrepancies in the results caused by the effects of the burning of the bushes thus giving false reflectance and landuse/landcover information. Thus further research is recommended to complement the results gotten from this research. Researches in this topic on this area were lacking thus more researches can be carried out in this area to create greater awareness for sustainable management our forest for it a great source of energy thus not compromising the future generation's ability to tap their own resources.. This will help to reduce the effects of climate change and health effects of using Fuelwood which has been the main cause of household pollution. The effectiveness of the tool to carry out research is great. The accuracy of its calculations and the ease with which tool can be used is amazing. The tool also has high temporal research update ability and can be used to carry out researches at the local and regional scale at a very short time giving this tool a high flexibility. The tool has a multidisciplinary use and makes it a warehouse of abilities to carryout research and thus a high advantage over many research tools. Thus this method of research should be used in researches and more updates of the tool be developed because its usefulness to research and mankind. 


\section{References}

Cameroon World Development Data, http://devdata.worldbank.org/atlasmdg/support/ info.php?cid=CMR\&lang=EN

Congalton, R. G. (1996). "Accuracy assessment: A critical component of land cover Mapping Gap Analysis. American Society of Photogrammetry and Remote Sensing, vol. pp. 119131.

Ekanade, O., Salami, A. T., Aborode, M. (1996). "Floristic changes in the tropical rainforest of South-western Nigeria". Malaysian Journal of Tropical Geography, 27(2), 7-13

Fon, N., Fomboh, A. A. and Neba C. (2006). "Developing biodiversity indicators as a tool for regulating development activities in and around protected areas and wetland regions in the North West province of Cameroon". Final Report: Community Initiative for Sustainable Development (COMINSUD).

Jagadeesh, K., et al (2001). "Mapping of Fuel Wood Trees in Kolar District using Remote Sensing Data and GIS", http://ces.iisc.ernet.in/energy/paper/fuelwood/a bstract.html

Lambin, E. F. (1997). "Modelling and monitoring land-cover change processes in tropical regions". Progress in Physical Geography, vol. 21, pp. 375-393.

Lambin, E. F., Geist H, Lepers E (2003). "Dynamics of land use and cover change in tropical regions". Annual Review Environmental Resources, vol. 28, pp. 205241.

Lunettaa, R. S. et al (2002). "Impacts of Vegetation dynamics on the identification of landcover change in a biologically complex community in North Carolina, USA". Remote Sensing of Environment, 82 (23), pp. 258-270

Mather, M. (1987) Computer Processing of Remotely-sensed Images: an Introduction. Wiley \& Sons.
Minoru, T. et al (2007) A Review of Energy in National MDG Reports UN, http://www.undp.org/energyandenvironment/su stainabledifference/

Myers, N. (1993) "Tropical forests: the main deforestationfronts".Environmental

Conservation,_ vol. 20, pp. 9-16.

Myers, N. (1991). "Tropical Forests: present status and future outlook", Climatic change, 19 (1-2), pp. 3-32

Oyinloye, R. O., Agbo B. F. and Aliyu Z. O. (2004). "Land Use/Land Cover Mapping in Osun State using NigeriaSat-1 Data". http://www.nasrda.gov.ng/docs/gueye.pdf

Pandey, V. N. (2000). "National Forest Cover assessment- Paper presented at the Biodiversity and Environment: Remote Sensing and Geographic Information System Perspective".

Salami, A. T, Balogun, E. E. (2006). "Utilization of NigeriaSat-1 and Other Satellites for Forest and Biodiversity Monitoring in Nigeria", National Space Research and Development Agency

(NASRDA) Monograph, Federal Ministry of Science and Technology, Abuja

Salami, A. T. (1999). "Vegetation Dynamics on the fringes of lowland humid tropical rainforest of South-western Nigeria- an assessment of environmental change with air photos and Landsat", International Journal of Remote Sensing, 20 (6), pp. 1169-1181.

Salami, A. T. and Akinyede, J. (2006). "Space technology for monitoring and managing forest in Nigeria", a paper presented at the International Symposium on Space and Forests,United Nations Committee on Peaceful Uses of Outer Space (UNOOSA), Vienna, Austria.

Singh, A. (1989). "Digital change detection techniques using remotely-sensed data",

International Journal of remote sensing, 10 (6), pp. 898-1003

Sumi, M. et al (2006) "Modelling household solid fuel use towards reporting of the Millennium Development Goal indicator". United Nations: Energy for Sustainable

Development, vol. X (3). 

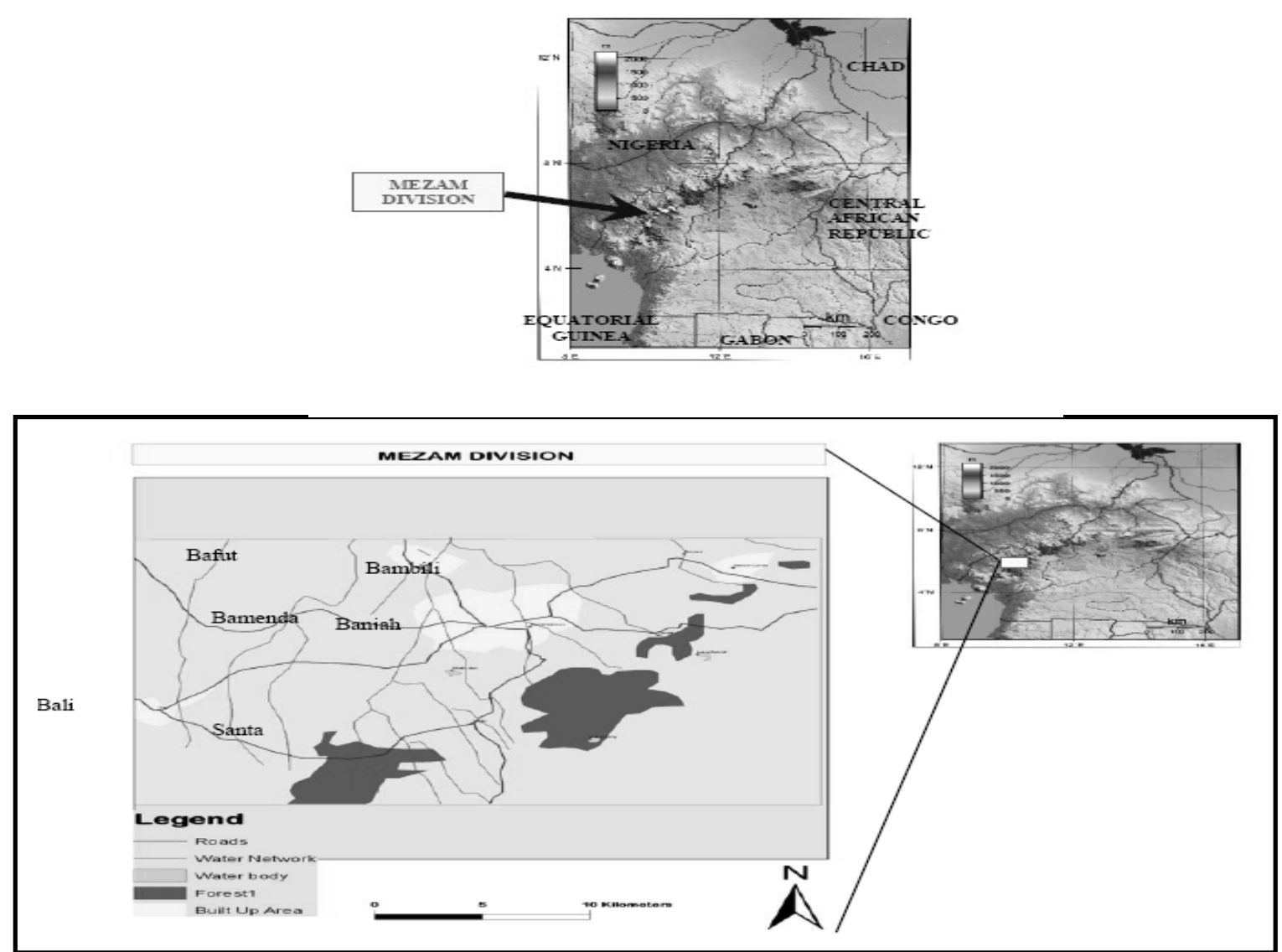

Figure 1: Site of Mezam Division in North West Province of Cameroon; the study area

(2a)

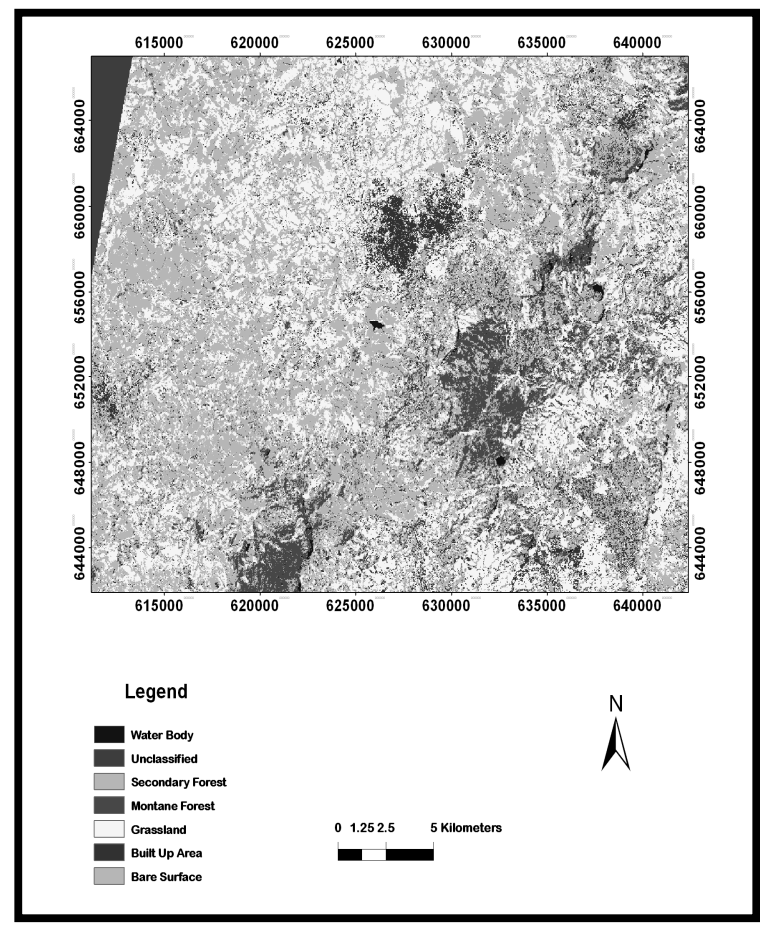

(2b)

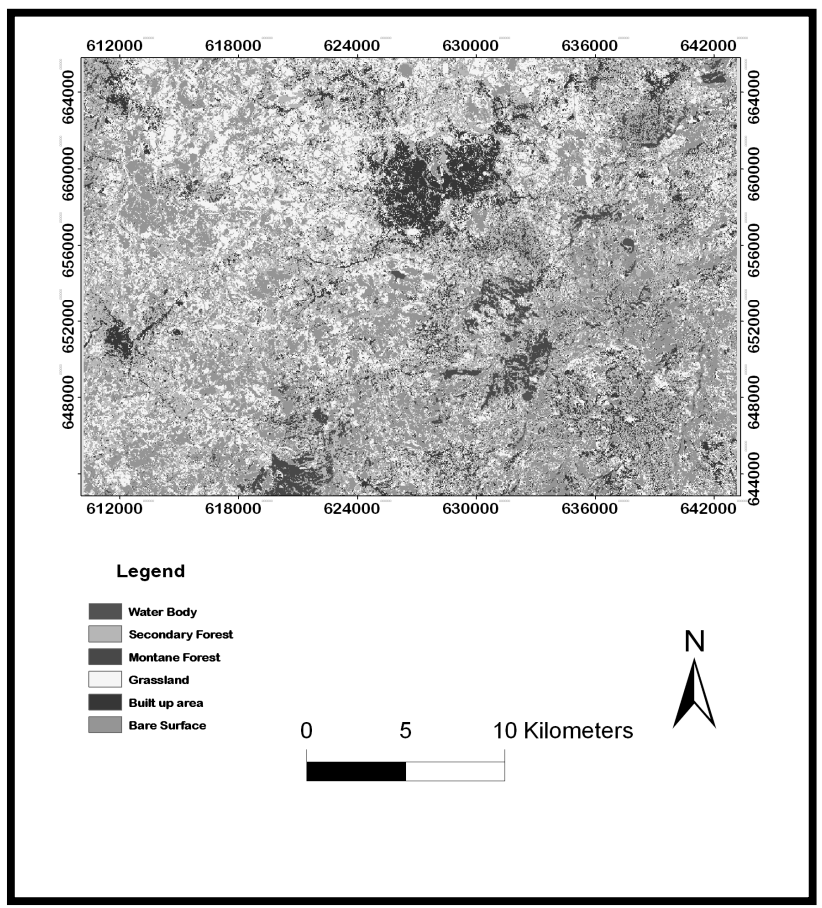

Figure 2a \& b, Results of processed satellite imageries of the land use/cover at Mezam division of Cameroon in 1988 (2a),and 2001 (2b) 
(2c)

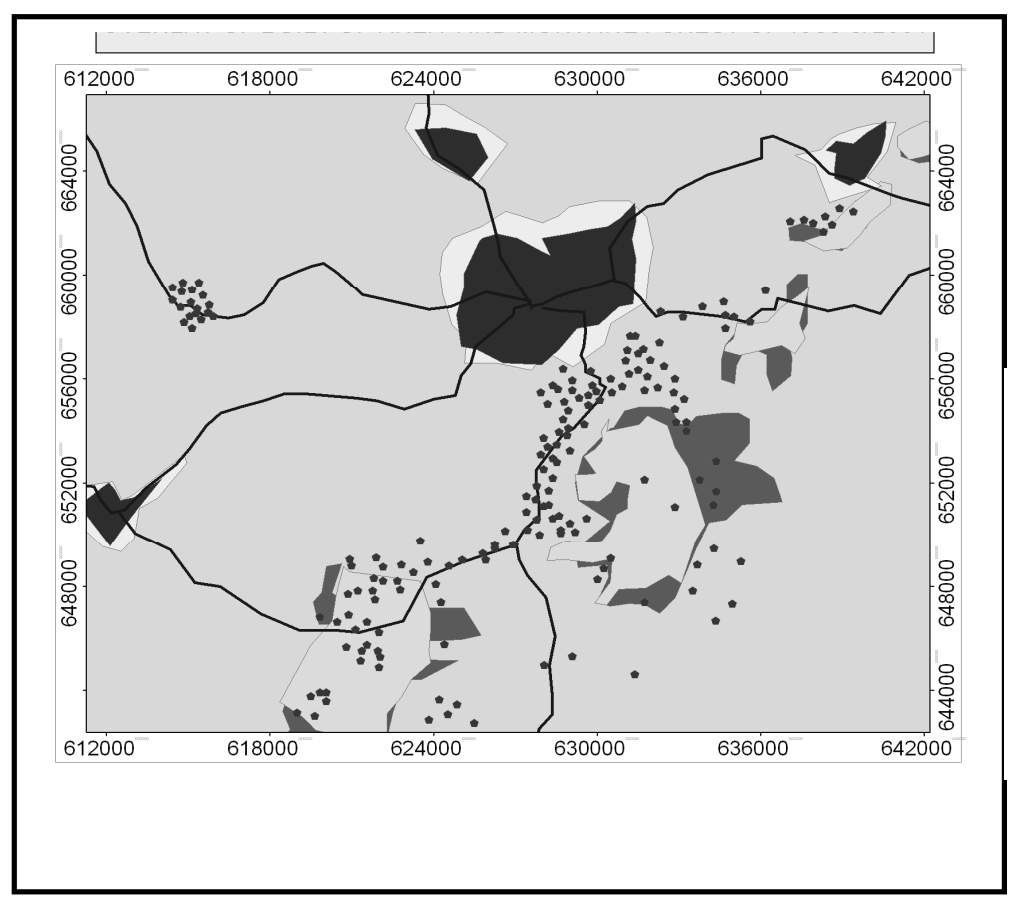

\section{Legend}

- Scattered settleme
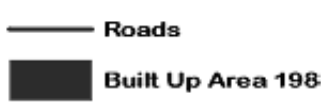

Built Up Area 198

Built Up Area 200

Forest 2001

Forest 1988

(2d)

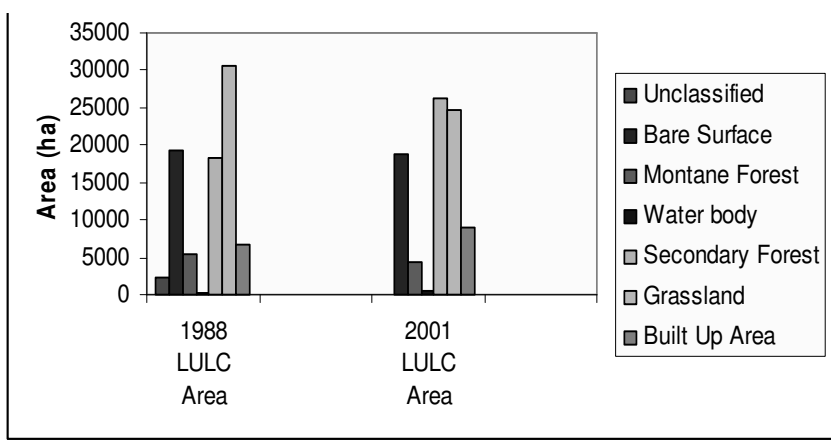

Figure 2c \& d: Results of comparison $(c \& d)$ satellite imageries of the land use/cover at Mezam division of Cameroon in 1988 and 2001 